\title{
The relationship between shock severity and the form of the antinociception observed in pentobarbital-anesthetized rats
}

\author{
JAMES W. GRAU, TAMARA E. KING, KYLE D. BURKS, \\ CHARLES F. KALLINA, and MARY W. MEAGHER \\ Texas A\&M University, College Station, Texas
}

\begin{abstract}
Three experiments are reported that explore the opioid/nonopioid nature of environmentally induced antinociception in pentobarbital-anesthetized rats. In Experiment 1, the minimum shock intensity and duration that elicits antinociception was established and two alternative descriptions of the tradeoff between shock intensity and duration were evaluated: the coulometric relationship (duration $\times$ intensity) and an extension of Stevens's power law (duration $\times$ intensity ${ }^{3.5}$ ). The results support the power law. In Experiments 2 and 3, the relationship between shock severity and the form of the antinociception elicited was examined. It was found that the least severe shock schedules produced a naltrexone-insensitive "nonopioid" antinociception. Increasing shock severity elicited an "opioid" antinociception that was attenuated by naltrexone. When shock severity was increased further, the antinociception again became naltrexone insensitive. Implications of the results are discussed.
\end{abstract}

Thirty years ago, Melzack and Wall (1965) proposed that a spinal "gate" could block the flow of afferent nociceptive information. It was further suggested that this gate could be closed in two ways: (1) directly, by afferent neural activity, and (2) indirectly, by supraspinal systems that exert their influence through descending fibers. Subsequent studies have confirmed that spinal mechanisms can attenuate the flow of nociceptive information (Basbaum \& Fields, 1984). However, this "antinociception" does not rely on just one gate. Instead, there appear to be multiple antinociceptive mechanisms within the spinal cord, each of which can be activated in a variety of ways (Basbaum \& Fields, 1984; Maier, 1989; Meagher, Chen, Salinas, \& Grau, 1993; Watkins \& Mayer, 1982, 1986; Watkins, Wiertelak, Grisel, Silbert, \& Maier, 1992).

Research in our laboratory has focused on detailing when and how these antinociceptive mechanisms are engaged (Meagher et al., 1993; Meagher, Grau, \& King, 1989, 1990). To address this question, we (Grau, Hyson, Maier, Madden, \& Barchas, 1981; Grau, 1987a, 1987b; Meagher et al., 1993; Meagher et al., 1989, 1990) and others (Lewis, Cannon, \& Liebeskind, 1980; Maier, 1989; Terman, Shavit, Lewis, Cannon, \& Liebeskind, 1984; Watkins \& Mayer, 1982) have used a number of physiological and pharmacological techniques that appear to distinguish distinct forms

\footnotetext{
This research was supported in part by grants from the National Science Foundation (BNS 881981) and National Institute of Mental Health (R01 MH48994) to J. W. G. and M.W. M. Portions of these data were presented at the annual meeting of the Society for Neuroscience, October 1992 (Anaheim, California). The authors thank Robin Joynes and Paul Illich for their help and advice. Correspondence concerning this article should be addressed to J. W. Grau, Department of Psychology, Texas A\&M University, College Station, TX 77843 (e-mail: j-grau@tamu.edu).
}

of antinociception and modes of activation. The most popular of these procedures involves testing whether the antinociception relies on an opiate synapse by assessing the impact of an opiate antagonist, such as naloxone or naltrexone. Using this technique, researchers have shown that there are at least two spinal antinociceptive systems, only one of which is affected by the systemic administration of an opiate antagonist (Lewis et al., 1980; Grau et al., 1981; Terman et al., 1984; Watkins \& Mayer, 1982). These two forms of antinociception are distinguished in the literature by the terms "opioid" and "nonopioid." In the present paper, we explore the conditions under which these antinociceptive systems are activated by a relatively "brief" exposure to shock. ${ }^{\prime}$ Our hope is to derive a set of mathematical relations that can be used to predict when each antinociceptive system will be engaged.

\section{Background}

The starting point for this work is a classic study published by Terman et al. (1984). According to them, shock severity determines whether an aversive stimulus engages the opioid or the nonopioid system. To test this hypothesis, they exposed different groups of rats to a single gridshock that varied in intensity and/or duration and assessed its impact on a spinally mediated tailflick test (D'Amour \& Smith, 1941). They found that the antinociception observed after the least severe shock schedules was naltrexone reversible (opioid). When shock intensity and/or duration were increased, the antinociception became naltrexone insensitive (nonopioid). Thus, a simple opioid-to-nonopioid transition was observed as a function of shock severity.

If shock severity determines the form of the antinociception observed, the next obvious question becomes: How do shock duration and intensity combine to determine net 
shock severity? A potential answer to this question was provided by Church, Raymond, and Bauchamp (1967), who explored the relationship between shock intensity and duration in a punishment paradigm. Over the range of parameters tested $(0.05-0.25 \mathrm{~mA}$ and $0.25-2.0 \mathrm{sec})$, they found that a twofold increase in intensity had about the same impact as a twofold increase in duration. Given this, they proposed that a simple "coulometric" relationship (duration $x$ intensity) determines shock severity. Fanselow (1984) and Terman et al. (1984) extended this notion to the realm of environmentally induced hypoalgesia, and suggested that a coulometric relationship could be used to predict whether the opioid or nonopioid system was engaged. According to this "coulometric hypothesis," low products activate the opioid system while larger products activate the nonopioid system.

In considering the studies conducted by Church et al. (1967), it is natural to assume that the impact of shock on operant responding is tied to its "perceived," or "subjective," aversiveness. However, in the situation studied by Terman et al. (1984), this does not appear to be the case, for exactly the same pattern of results was obtained irrespective of whether subjects were awake or anesthetized with pentobarbital. In fact, other work suggests that the antinociception survives decerebration (Klein, Lovaas, Terman, \& Liebeskind, 1983; Watkins, Kinscheck, \& Mayer, 1983). These observations are important for two reasons.
First, the results suggest a solution to an ethical dilemma: Given that these antinociceptive systems are engaged only by relatively severe stimuli, it is imperative that we use every means possible to minimize the subject's pain and suffering. We can address this issue by testing subjects while they are anesthetized and presumably "feel" less pain. Second, these observations have implications for the way in which the antinociceptive systems are engaged. From studies of stimulation-produced hypoalgesia, it is clear that neural systems within the brainstem can produce either an opioid or a nonopioid antinociception, and that which mechanism is engaged depends on the site of stimulation (Cannon, Prieto, Lee, \& Liebeskind, 1982). These findings, together with the observation that the antinociception observed survives decerebration, led researchers to propose that afferent nociceptive information could "directly" activate the antinociceptive systems at the level of the brainstem (this is illustrated on the left side of Figure 1). As recently as 1989 (Grau, 1987a; Maier, 1989), it appeared that only one other connection was required to account for the majority of results - a forebrain-dependent pathway that allowed "higher psychological mechanisms," sensitive to the environmental relations, to modulate the activation of the opioid system.

We (Grau, 1987a, 1987b; Meagher et al., 1993; Meagher et al., 1989, 1990) have been systematically testing components of this functional model. Our first studies were mo-
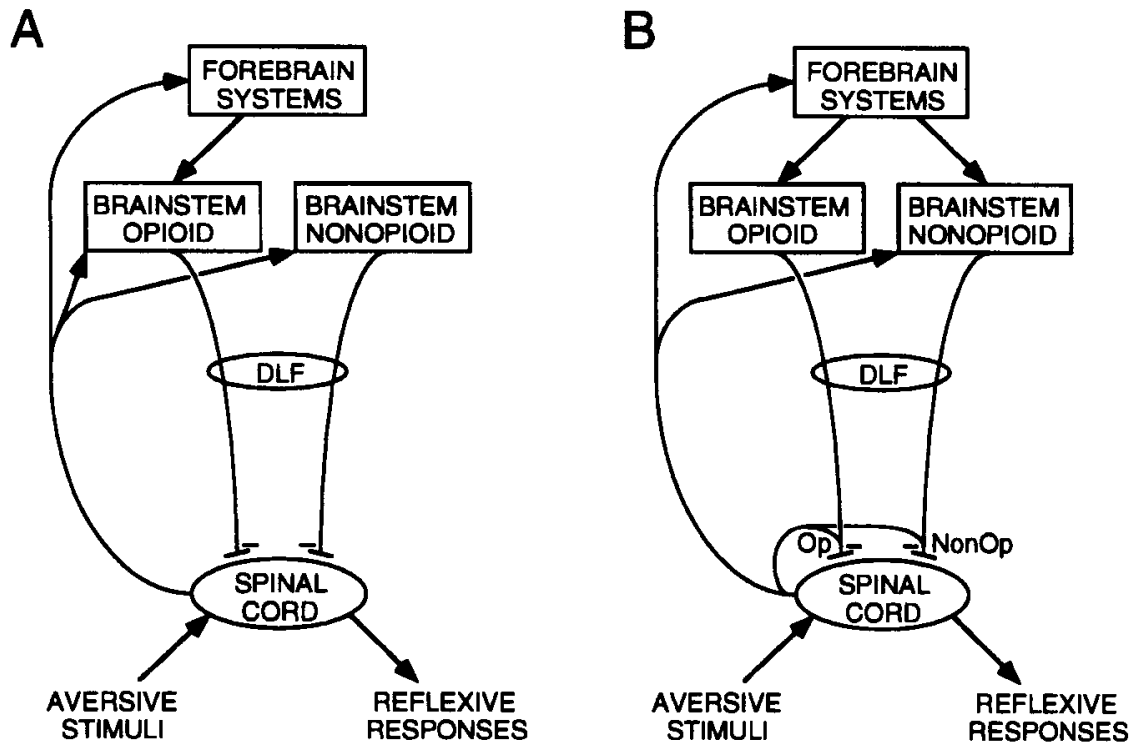

Figure 1. Two functional models of pain modulation. Panel A illustrates the most widely accepted model of pain modulation, one that allows for direct activation of the opioid and nonopioid hypoalgesic systems at the level of the brainstem. To account for acquired changes in pain reactivity, it is also generally assumed that forebrain systems can activate the opioid system. Panel B summarizes the model outlined in Meagher et al. (1993; Meagher et al., 1990). In both models, neural systems within the brainstem can produce either an opioid (Op) or nonopioid (NonOp) antinociception (indicated by a "-") at the level of the spinal cord by fibers that pass through the dorsolateral funiculus (DLF). The model proposed by Meagher et al. differs in that it assumes that (1) forebrain systems can activate the nonopioid antinociceptive mechanism as well as the opioid system; (2) at the level of the brainstem, only the nonopioid system can be activated by afferent nociceptive signals; and (3) both forms of antinociception can be produced by means of intraspinal pathways. 
tivated by an apparent conflict. We had found that exposure to mild tailshock (three $0.75-\mathrm{sec}, 1.0-\mathrm{mA}$ shocks) elicited both a transient nonopioid and a long-lasting opioid hypoalgesia on the tailflick test in awake rats (Grau, 1984, 1987a). However, unlike the hypoalgesia observed by Terman et al. (1984), the hypoalgesia observed after mild shock appeared to depend on higher psychological/ neural systems in the forebrain because it was eliminated by decerebration, lesions of the frontal cortex, and anesthesia (Grau, 1987a; Meagher et al., 1989, 1990). We speculated that different results were obtained because we used much briefer shocks. Supporting this, we showed that longer tailshocks $(25-\mathrm{sec})$ produced a nonopioid antinociception that was eliminated by a spinal transection but not by decerebration or more rostral lesions (Meagher et al., 1993; Meagher et al., 1989, 1990).

What was missing was evidence that an opioid antinociceptive mechanism could also be directly activated at the level of the brainstem. To explore this issue, we derived the minimum shock intensity and duration needed to elicit antinociception in decerebrate rats (Meagher et al., 1993). We then performed tests to determine whether the form of the antinociception observed in decerebrate subjects varied as a function of shock severity. In no case did we find any evidence that the opioid system could be directly engaged; in all cases, the antinociception was naltrexone insensitive. Furthermore, the coulometric relationship did not accurately predict when the nonopioid system was activated; increasing shock intensity had a greater impact than increasing shock duration.

We then explored whether more severe tailshocks could produce antinociception in spinalized rats (Meagher et al., 1993). We found that when shock intensity was increased to the range used by Terman et al. (1984), a strong antinociception was obtained. Moreover, the form of the antinociception varied as a function of shock severity; as reported by Terman et al. (1984), the least severe shocks produced an opioid antinociception, while the most severe shocks produced a nonopioid antinociception. However, the coulometric relationship did not accurately predict when the antinociceptive systems were engaged. Again, increasing shock intensity had a greater impact than increasing shock duration. Given this, we argued (Meagher et al., 1993) that a relationship based on Stevens's (1962) power law might provide a better measure of shock severity. Stevens found that judgments of shock intensity (in milliamperes) exhibited expansion, instead of compression, and that a power function with an exponent of approximately 3.5 nicely described the relationship between subjective and physical intensity (Stevens, Carton, \& Shickman, 1958). Given this, we proposed that shock severity was a function of duration $X$ intensity 3.5 . (In the remainder of the paper we will refer to this relationship as the "power law.")

\section{Experimental Predictions and Rationale}

Thus, our studies using reduced preparations (spinalized, decerebrate, and lesioned subjects) suggest a story very different from the one originally outlined by Terman et al. (1984) and subsequently extended by Grau (1987a, 1987b) and Maier (1989). Focusing on the lower level modes of activation (those within the brainstem and spinal cord), the results obtained by Terman et al. imply that a simple opioid-to-nonopioid transition should be observed as shock severity increases, a transition that reflects the sequential activation of the brainstem opioid and nonopioid systems by afferent nociceptive information. In contrast, our work suggests that afferent nociceptive information can activate antinociceptive systems through either spinal pathways or a brainstem loop (see the right side of Figure 1). Of these low-level pathways, the one that relies on brainstem systems appears to be the first engaged, and it does not depend on an opioid synapse. Exposure to even more severe stimuli activates an opioid first, and then a nonopioid, antinociceptive system through intraspinal pathways. Putting this all together, our results imply that a nonopioid-to-opioid-to-nonopioid transition should be observed as shock severity is increased.

However, there is a basic problem in generalizing from our results to those reported by Terman et al. (1984), for our conclusions are based on very different preparations. Because we sought to isolate the level of the neural axis that mediates these antinociceptive effects, we tested our subjects after various surgical manipulations. In contrast, Terman et al. based their conclusions on results obtained in intact pentobarbital-anesthetized rats. It is possible that a different pattern of results was obtained because the subjects were stressed by surgery or the transections "released" lower level mechanisms from tonic inhibition. Given this, we needed to evaluate whether similar results would be obtained if we used the same preparation employed by Terman et al., a preparation in which unoperated rats are tested while anesthetized with pentobarbital. Using this procedure, we first established the minimum shock intensity and duration needed to produce antinociception in pentobarbital anesthetized rats (Experiment 1). In Experiments 2 and 3, we then explored the relationship between shock severity and the form of the antinociception observed.

\section{EXPERIMENT 1}

Our first experiment was designed to establish the minimum shock intensity and duration required to elicit antinociception in pentobarbital-anesthetized rats. As in earlier studies (Grau, 1987a; Meagher et al., 1993; Meagher et al., 1990), antinociception was induced by applying three tail shocks. On the basis of this work, we expected that 25-sec shocks would produce antinociception when intensity reached $0.5 \mathrm{~mA}$. Conversely, when shock intensity was held constant at $1.0 \mathrm{~mA}$, we expected antinociception to appear when duration reached $1.5 \mathrm{sec}$.

Experiment 1 also evaluated the relative merits of two measures of shock severity (Meagher et al., 1993; Terman et al., 1984): the coulometric relationship and the power law. In prior studies, we (Grau, 1987b; Meagher et al., 1993) had found that a brief intense shock had a greater impact than a long weak shock, an outcome that favors the power law. For example, in decerebrate rats three $1.5-\mathrm{sec} 1.0-\mathrm{mA}$ shocks produce a much stronger antinociception than do 
three $25-\mathrm{sec} 0.3-\mathrm{mA}$ shocks, even though the latter shock schedule yields a greater coulometric product (see Figure 2). It could be argued, however, that the antinociceptive systems are not activated until a minimum intensity and duration has been reached. From this perspective, long weak shocks may fail to produce antinociception simply because their intensities are subthreshold. Given this, a fair test of the coulometric relationship requires that we use intensity and duration values that are clearly suprathreshold. We anticipated that when duration was held constant, antinociception would emerge at an intensity of $0.5 \mathrm{~mA}$, and that when intensity was held constant, antinociception would appear when duration reached $1.5 \mathrm{sec}$. Such a pattern of results would imply that the values of $1.5 \mathrm{sec}$ and $0.5 \mathrm{~mA}$ lie above the hypothesized threshold. Given this, the coulometric hypothesis would predict that a $3.0-\sec 0.5-\mathrm{mA}$ shock would have the same effect as a $1.5-\mathrm{sec} 1.0-\mathrm{mA}$ shock, since both yield the same coulometric product. By contrast, the power law predicts that the brief intense shock will have a greater impact than the long but weak shock.

\section{Method}

Subjects. The subjects were 48 male Sprague-Dawley rats obtained from Harlan (Houston, TX). The rats were 100-120 days old and weighed between 420 and $500 \mathrm{~g}$. The animals were individually housed and maintained on a 12:12-h light:dark cycle, with testing occurring during the last $6 \mathrm{~h}$ of the light part of the cycle. Food and water were available ad lib.

Apparatus. The subjects were tested while restrained in $22-\mathrm{cm}$ long, 6.8-cm ID Plexiglas tubes. The front of each tube was covered by a Plexiglas sheet. Inside the tube was a flat rectangular base on which the rat could lie $(5.5 \mathrm{~cm}$ wide and $5.3 \mathrm{~cm}$ from the top of the

\section{COULOMETRIC RELATION:}

SHOCK SEVERITY $=$ DURATION $X$ INTENSITY

\begin{tabular}{|c|c|c|c|c|c|c|c|}
\hline & \multicolumn{6}{|c|}{ NET TIME IN SEC } \\
\hline & & 2.25 & 4.50 & 6.00 & 9.00 & 75.0 & 225.0 \\
\hline \multirow{5}{*}{ 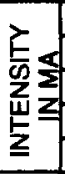 } & 0.3 & & & & & 22.5 & \\
\hline & 0.5 & & & & 4.50 & 37.5 & \\
\hline & 1.0 & 2.25 & 4.50 & & & 75.0 & \\
\hline & 1.5 & & & & & 112.5 & \\
\hline & 3.0 & & & 18.0 & & 225.0 & 675.0 \\
\hline
\end{tabular}

\section{POWER LAW:}

SHOCK SEVERITY = DURATION $X$ INTENSITY 3.5

\begin{tabular}{|c|c|c|c|c|c|c|c|}
\hline & \multicolumn{6}{|c|}{ NET TIME IN SEC } \\
\hline & & 2.25 & 4.50 & 6.00 & 9.00 & 75.0 & 225.0 \\
\hline \multirow{5}{*}{ 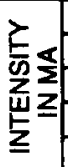 } & 0.3 & & & & & 1.13 & \\
\hline & 0.5 & & & & 0.80 & 6.60 & \\
\hline & 1.0 & 2.25 & 4.50 & & & 75.0 & \\
\hline & 1.5 & & & & & 309 & \\
\hline & 3.0 & & & 281.0 & & 3507 & 10521 \\
\hline
\end{tabular}

Figure 2. Predicted shock severity values derived from the coulometric relationship (upper panel) and power law (lower panel) for the shock duration/intensity values used in Experiments 1 and 2. Note that, because three shocks were given, net time equals shock duration times three. tube). The exterior surface of the tubes was covered with duct tape to minimize the effect of distracting stimuli (Grau, 1987a; Meagher, Barter, King, \& Grau, 1995). Ventilation holes were drilled into the top middle portion of each tube. The rats were held in the tubes by a band of adhesive tape that enclosed the rear opening just above their tails. This allowed the tail, which projected between the adhesive band and the base of the tube, to move freely. Each tube was held in a sound-attenuating chamber.

Tailshock was provided by a $660-\mathrm{V}$ transformer which, in combination with a $2.03-\mathrm{M} \Omega$ series resistor, provided a constant-current shock source. Shock was applied to the tail through electrodes constructed from a modified fuse clip. The electrode plates were lightly coated with electrode paste and taped to the rat's tail approximately $15 \mathrm{~cm}$ behind the rear of the tube.

A radiant-heat tailflick device was used to assess changes in nociception. The radiant-heat source was a 375-W movie light (Sylvania, Type EBR), which was located $18 \mathrm{~cm}$ above the base of the apparatus. A condenser lens was positioned $8 \mathrm{~cm}$ below the light to focus the radiant heat source onto the tail. The aluminum base of the device had a V-shaped groove cut into it $(0.8 \mathrm{~cm}$ wide and $0.4 \mathrm{~cm}$ deep), in which the rat's tail was positioned. Trials were automatically terminated by a lateral movement of the tail (minimum $0.5 \mathrm{~cm}$ ), which was detected by a photocell positioned below the groove. A timer automatically recorded the duration of the trial to the nearest $0.01 \mathrm{sec}$. If a response did not occur within the first $8 \mathrm{sec}$, the trial was manually terminated to prevent tissue damage.

The apparatus was located in an isolated room. A space heater maintained the room temperature at approximately $26.0^{\circ} \mathrm{C}$. This fan, in combination with the chamber fans, provided a background noise level of about $60 \mathrm{~dB}$.

Procedure. The subjects were removed from their home cages, injected (i.p.) with $40-\mathrm{mg} / \mathrm{kg}$ sodium pentobarbital (V-Pento; distributed by A-J Buck \& Son), and returned to their home cages. This dosage is routinely used in our laboratory to prepare subjects for surgery. It produces a moderate-to-strong anesthesia with little evidence of respiratory dysfunction. Twenty minutes after the injection, the subjects were checked to make sure they were flaccid and breathing normally. They were then placed in the restraining tubes and given 15 min to acclimate. Next, baseline nociception was tested by administering four tailflick tests at 2-min intervals. The last three trials were averaged to provide a measure of the rats' baseline nociceptive thresholds.

Immediately after the last baseline test, the shock electrodes were attached to the rats' tails with adhesive tape. The rats were then exposed to one of six shock schedules $(n=8)$. In each shock condition, three shocks were administered spaced $20 \mathrm{sec}$ apart (from shock termination to onset). For two of the groups, shock duration was held constant at $25 \mathrm{sec}$ and the intensity was set to either 0.3 or $0.5 \mathrm{~mA}$. Another two groups had shock intensity held constant at $1.0 \mathrm{~mA}$ and its duration was set to either 0.75 or $1.5 \mathrm{sec}$. The fifth group received $0.5-\mathrm{mA}$ shocks that were $3 \mathrm{sec}$ long. The last group served as the unshocked controls. Two minutes after the last shock, or an equivalent period of restraint, tailflick latencies were assessed five more times at 2 -min intervals. The subjects were then removed and, once again, inspected to make sure that they were breathing normally and were still flaccid.

\section{Results}

Mean tailflick latencies are depicted in Figures 3 and 4. The top panel of Figure 3 displays the data from subjects that received 25 -sec shocks that varied in intensity; the bottom panel depicts the data from subjects that received 1.0-mA shocks that varied in duration. For comparison, the data obtained from the unshocked controls are presented in both panels. It is apparent that the 25 -sec shocks did not elicit antinociception until shock intensity was in- 


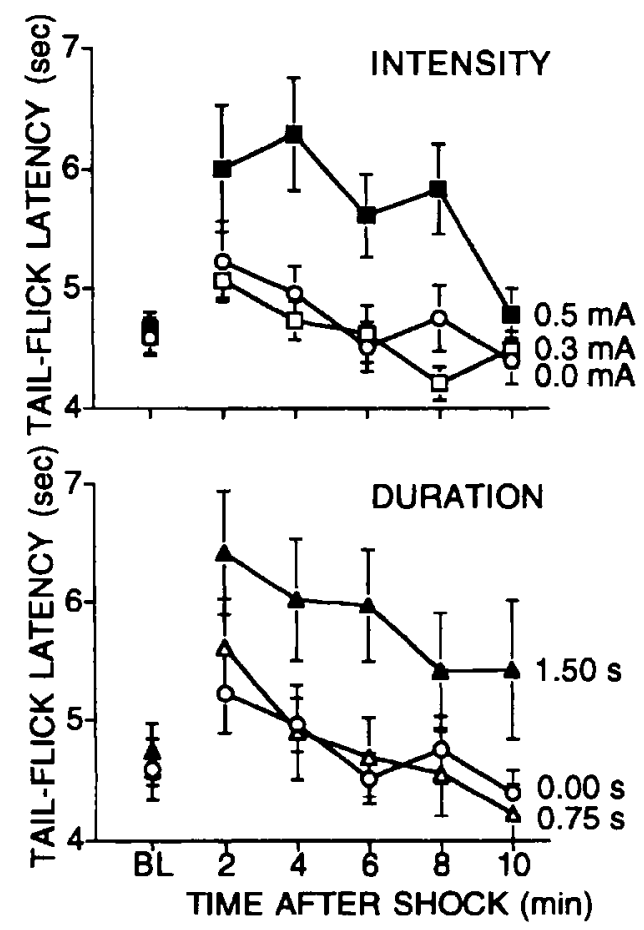

Figure 3. Tailfick latencies observed in rats that were pentobarbital-anesthetized and had received 25-sec shocks that varied in intensity (top panel) or 1.0-mA shocks that varied in duration (bottom panel). Subjects in the intensity condition received 0.0 mA (open circles), three 25-sec 0.3-mA shocks (open squares), or three 25-sec 0.5-mA shocks (filled squares). Subjects in the duration condition received three $1.0-\mathrm{mA}$ shocks that were $0.0 \mathrm{sec}$ (open circles), $0.75 \mathrm{sec}$ (open triangles), or $1.5 \mathrm{sec}$ (filled triangles) in duration. Error bars indicate the standard errors.

creased to $0.5-\mathrm{mA}$, and that the $1.0-\mathrm{mA}$ shocks did not elicit antinociception until shock duration was increased to $1.5 \mathrm{sec}$. Figure 4 depicts the data from the shock schedules that had the same coulometric product. It is clear that the $1.5-\mathrm{sec} / 1.0-\mathrm{mA}$ shocks elicited antinociception while the $3.0-\mathrm{sec} / 0.5-\mathrm{mA}$ shocks did not.

Statistical analyses confirmed these impressions. An analysis of variance (ANOVA) performed on the mean baseline tailflick scores showed that the groups did not differ prior to shock $[F(5,42)<1.0, p>.05]$. An analysis of the data obtained 2 to 10 min after shock revealed a significant effect of both shock condition $[F(5,42)=3.84$, $p<.01]$ and test trial $[F(4,168)=11.24, p<.001]$. The interaction between shock condition and test trial was not significant $[F(20,168)<1.0, p>.05]$. Post hoc comparisons with Duncan's multiple range test showed that the $25-\mathrm{sec} /$ $0.5-\mathrm{mA}$ and $1.5-\mathrm{sec} / 1.0-\mathrm{mA}$ shocked groups were significantly different from the groups that received $25-\mathrm{sec} /$ $0.3-\mathrm{mA}$ or $0.75-\mathrm{sec} / 1.0-\mathrm{mA}$ shocks or no shock. In addition, the $1.5-\mathrm{sec} / 1.0-\mathrm{mA}$ shock schedule produced greater antinociception than did the $3.0-\mathrm{sec} / 0.5-\mathrm{mA}$ shock schedule.

\section{Discussion}

The pattern of results obtained in subjects that were pentobarbital-anesthetized was nearly identical to that ob- tained in decerebrate subjects (Meagher et al., 1993). Thus, as found in decerebrate rats, 25 -sec shocks did not elicit antinociception until shock intensity reached $0.5 \mathrm{~mA}$. Similarly, 1.0-mA shocks did not elicit antinociception until shock duration reached $1.5 \mathrm{sec}$.

The results yielded little evidence for the coulometric hypothesis (Terman et al., 1984). One problem is that three brief intense shocks $(1.5 \mathrm{sec} / 1.0 \mathrm{~mA})$ elicited antinociception, while three mild long shocks $(25 \mathrm{sec} / 0.3 \mathrm{~mA})$ did not, and this was true even though the latter shock schedule had a coulometric product that was five times larger (see Figure 2). More importantly, when we compared two shock schedules $(1.5 \mathrm{sec} / 1.0 \mathrm{~mA}$ and $3.0 \mathrm{sec} / 0.5 \mathrm{~mA})$ that had the same coulometric product and utilized shock intensity and duration values greater than the minimum needed to elicit antinociception in either decerebrate or pentobarbital anesthetized subjects, the coulometric hypothesis failed - the brief but intense shocks produced antinociception, while the long but mild shocks did not. Again, it appears that shock intensity contributes more to shock severity than does shock duration, as predicted by the power law. Interestingly, recent evidence suggests that the same is true for people - that intensity contributes much more than duration in judgments of stimulus severity (Kahneman, Frederickson, Schreiber, \& Redelmeier, 1993).

\section{EXPERIMENT 2}

Having established the minimum shock intensity and duration needed to elicit antinociception in pentobarbitalanesthetized rats, we were in a position to evaluate the relationship between shock severity and the form (naltrexone sensitivity) of the antinociception observed. According to Terman et al. (1984), the least severe shock schedules should produce an antinociception that is naltrexone reversible. As shock intensity and/or duration is increased, the antinociception should become naltrexone insensitive. By contrast, our work suggests that the least severe shock parameters should engage the nonopioid brainstem system. As shock severity is increased, intraspinal connections should produce first an opioid, then a nonopioid antinociception.

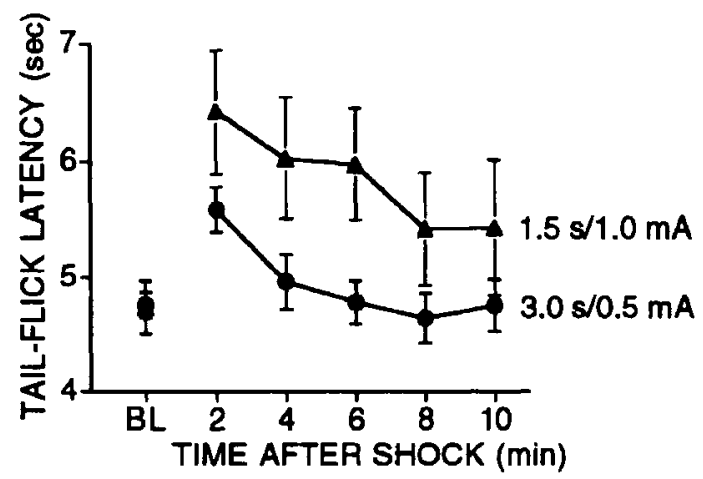

Figure 4. Tailfick latencies observed in rats that were pentobarbital-anesthetized and exposed to three 1.5-sec 1.0-mA shocks (filled triangles) or three 3.0-sec 0.5-mA shocks (filled circles). Error bars indicate the standard errors. 
Thus, whereas Terman's study suggests that a simple opioidto-nonopioid transition should be obtained as shock severity is increased, our work suggests a more complex nonopioid-to-opioid-to-nonopioid transition.

\section{Method}

Subjects and Apparatus. The subjects were 128 rats of the same age, sex, and strain as those used in Experiment 1. The apparatus was also the same.

Procedure. The subjects received an i.p. injection of pentobarbital $(40 \mathrm{mg} / \mathrm{kg})$ as described in Experiment 1 . Twenty minutes later, half the subjects received a subcutaneous injection of naltrexone $(14 \mathrm{mg} / \mathrm{kg}$ ). This dose of naltrexone was chosen because (1) past work had shown that it was as large as, or larger than, the dose of naltrexone needed to eliminate the putative opioid hypoalgesia observed in a variety of experimental situations (Grau, 1987a; Grau, Biles, \& Illich, 1991; Grau et al., 1981; Hyson, Ashcraft, Drugan, Grau, \& Maier, 1982; Maier, 1989; Maier et al., 1980); and (2) a similar dose had been used in past studies, and comparisons across studies were of interest (Grau, 1987a; Grau et al., 1981; Grisel, Fleshner, Watkins, \& Maier, 1993; Maier, 1989; Terman et al., 1984). (It is important to remember that the purpose of this study was to resolve some apparent conflicts [cf. Terman et al., 1984] and to clarify when different antinociceptive mechanisms were engaged. Our hope is that this work will provide the foundation needed to identify the particular neural structures and mechanisms involved. Of course, this will require the use of more selective pharmacological/physiological techniques.) The remaining half received saline injections. The subjects were then placed in the restraining tubes and given $15 \mathrm{~min}$ to acclimate. Next, baseline tailflick latencies were assessed as described in Experiment 1 . The subjects were then exposed to one of eight shock schedules. Subjects in three of these conditions received 25 -sec shocks that had an intensity of $0.5,1.0$, or $1.5 \mathrm{~mA}$. Three other groups received $3.0-\mathrm{mA}$ shocks that were $2.0,25$, or $75 \mathrm{sec}$ in duration. Another shock group received 1.0 -mA shocks that were $1.5 \mathrm{sec}$ in duration, and the last group served as the unshocked controls. In each shock condition, the subjects received three shocks spaced $20 \mathrm{sec}$ apart. Because shock duration was manipulated, we were forced to choose between equating total session duration (and delaying the onset of testing) or keeping the time since the termination of the last shock and the onset of testing constant. We chose to keep the latter variable constant because this procedure had been used in prior studies (Meagher et al., 1993) and because the antinociception observed after brief shock could decay during the rest interval if it was extended to maintain a constant session duration. Thus, for all conditions, tailflick latencies were assessed five times at 2-min intervals starting 2 min after the last shock.

\section{Results}

The mean tailflick scores are depicted in Figure 5. As one would expect, increasing shock severity increased the magnitude of the antinociception observed. Naltrexone did not attenuate the antinociception elicited by the three least severe shock schedules, that is, those that employed shock intensities of $1.0 \mathrm{~mA}$ or less. Focusing on the data obtained from subjects exposed to 25 -sec shocks, it appears that a naltrexone-sensitive antinociception emerged after shock intensity was increased to $1.5 \mathrm{~mA}$. When shock intensity was set to $3.0 \mathrm{~mA}$, brief shocks elicited a naltrexonesensitive antinociception and much longer shocks produced a naltrexone-insensitive antinociception.

Statistical analyses supported these impressions. An ANOVA performed on the baseline scores showed that the groups did not differ prior to shock (all $F \mathrm{~s}<1.33, p>.05$ ).
An analysis of the postshock data revealed that shock had a significant impact $[F(7,112)=13.26, p<.001]$. Importantly, the interaction term confirmed that the impact of shock depended on drug treatment $[F(7,112)=2.38, p<$ $.05]$. The main effect of drug treatment was marginally significant $[F(1,112)=3.16, p<.08]$. There was also a significant trials effect $[F(4,448)=9.46, p<.001]$. However, the trials effect did not interact with any of the betweensubjects treatments (all $F \mathrm{~s}<1.80, p>.05$ ). To further analyze the main effect of shock treatment, the group means, collapsed across drug treatment, were compared with Duncan's multiple range test. This test revealed that all of the shock schedules produced a significant hypoalgesia as compared with the unshocked controls. In addition, the 25 -sec/ $0.5-\mathrm{mA}$ shock schedule produced an antinociception that was significantly smaller than that produced by the other six shock schedules. Finally, the most severe shock schedule, $75 \mathrm{sec} / 3.0 \mathrm{~mA}$, produced a hypoalgesia that was significantly greater than that produced by the two brief shock schedules, $1.5 \mathrm{sec} / 1.0 \mathrm{~mA}$ and $2 \mathrm{sec} / 3.0 \mathrm{~mA}$. Next, to further analyze the nature of the shock $\times$ drug interaction, we computed the simple main effect of drug treatment under each shock condition. These analyses confirmed that naltrexone attenuated the antinociception produced by the 3-mA shocks when shock duration was set to either 2 or $25 \mathrm{sec}$ (both $F \mathrm{~s}>4.90, p<.05$ ). In addition, naltrexone attenuated the antinociception elicited by the $25-\mathrm{sec} / 1.5-\mathrm{mA}$ shock schedule $[F(1,112)=8.03, p<.005]$. Naltrexone did not have a significant impact on the antinociception elicited by any of the other shock schedules (all $F_{\mathrm{S}}<1.40$, $p>.05$ ).

\section{Discussion}

We found that the least severe shock parameters, which generate a naltrexone-insensitive antinociception in decerebrate rats (Meagher et al., 1993; Meagher et al., 1990), also produced a nonopioid antinociception in pentobarbitalanesthetized subjects. As previously found in spinalized subjects (Meagher et al., 1993), more severe shocks generated an antinociception that was attenuated by naltrexone. Finally, the most severe shock schedule, which produced a nonopioid antinociception in spinalized rats, also generated a nonopioid antinociception in pentobarbital-treated rats. Thus, we failed to observe a simple opioid-to-nonopioid transition as a function of shock severity (Terman et al., 1984). Instead, our results suggest that the brainstem nonopioid, spinal opioid, and spinal nonopioid are sequentially activated as shock severity is increased (Meagher et al., 1993).

An outcome that was not anticipated by either relationship concerned the impact of three 25-sec 0.5-mA tailshocks, which generated an antinociception that was weaker than that produced by three 1.5 -sec 1 -mA shocks. The coulometric relationship anticipated the opposite outcome (see Figure 2); consequently, this finding poses further problems for this relationship. However, the results are also problematic for the power law because it predicted that the two shock schedules would generate comparable lev- 

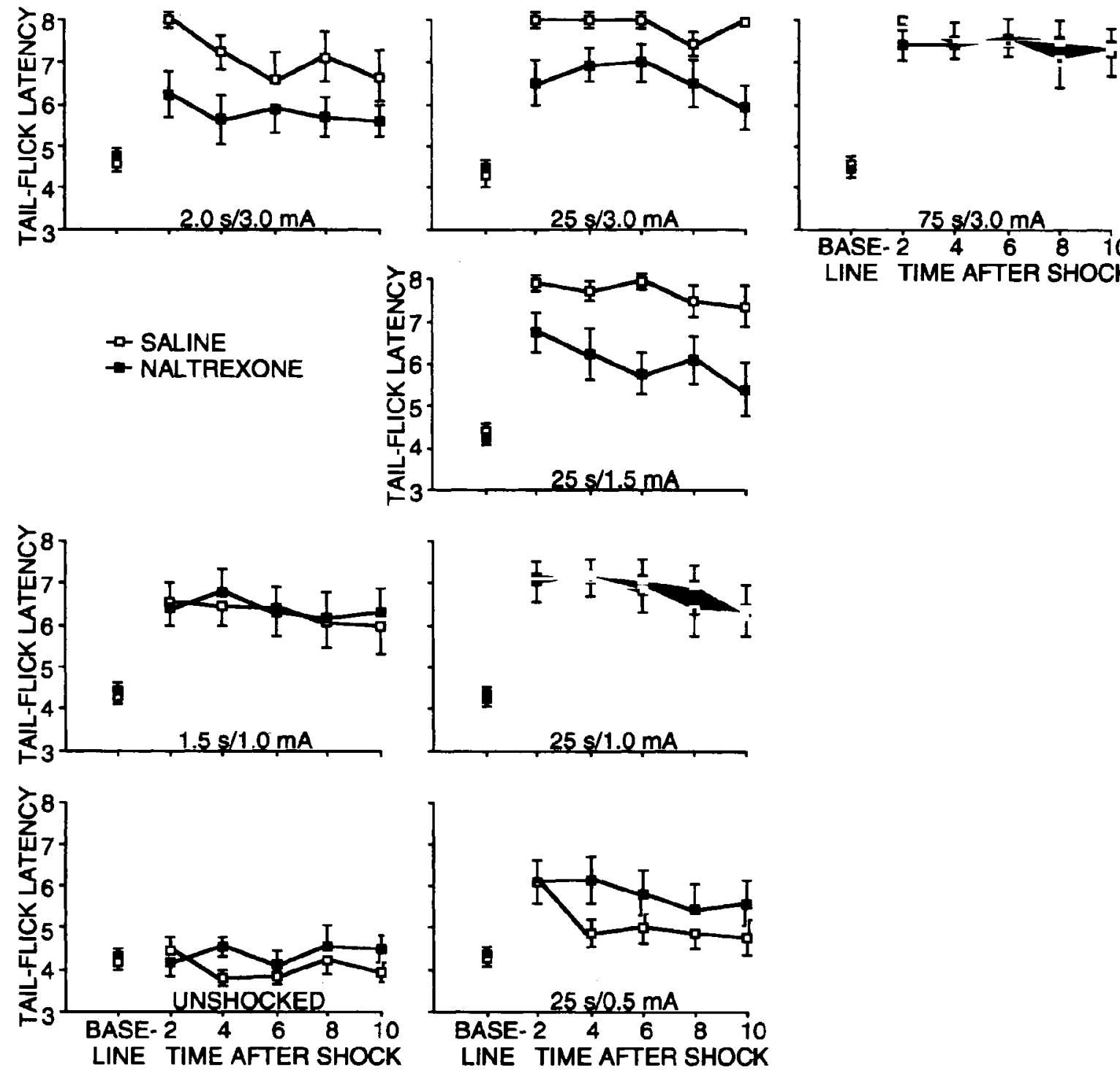

Figure 5. Tailflick latencies observed in saline-treated (open symbols) and naltrexone-treated (filled symbols) pentobarbitalanesthetized rats that were exposed to one of eight different shock schedules. The center column depicts the data obtained from subjects exposed to three 25-sec shocks that varied in intensity from $0.5 \mathrm{~mA}$ (bottom) to $3.0 \mathrm{~mA}$ (top). Shorter durations are depicted to the left and longer durations to the right. The data obtained from the unshocked controls is displayed in the lower left panel. Error bars indicate the standard errors.

els of antinociception (see Figure 2 and note 3 ). Indeed, in an earlier study, similar levels of antinociception were observed (see Figure 1, Meagher et al., 1993). Consequently, it is not clear whether this problematic finding will prove to be reliable.

\section{EXPERIMENT 3}

Experiment 2 showed that three $1.5-\mathrm{sec} 1.0-\mathrm{mA}$ shocks elicited a naltrexone-insensitive antinociception in pentobarbital anesthetized rats. Although this outcome is consistent with our prior research, it appears to run counter to a report by Maier (1989). Maier found that a single 5-sec 1.0-
$\mathrm{mA}$ tailshock generated a transient naltrexone-reversible antinociception in pentobarbital-anesthetized rats. Given the small net difference in shock applied $(4.5 \mathrm{sec}[3 \times$ 1.5 ] of $1.0 \mathrm{~mA}$ vs. $5.0 \mathrm{sec}$ of $1.0 \mathrm{~mA}$ ), that both studies used Sprague-Dawley rats, and that the apparatus used were very similar, it is troubling that different outcomes were obtained. There are, however, a number of subtle differences that could account for the discrepancy. For example, Maier (1989) used somewhat younger subjects, slightly smaller uncovered restraining tubes, a single shock, and a shorter acclimation period. Given these differences, we wondered whether we too would observe an opioid hypoalgesia in pentobarbital-anesthetized rats if we tested subjects under 
similar conditions. Our strategy was to mimic the conditions used by Maier (1989) as closely as possible. If, under these conditions, a naltrexone-reversible antinociception was observed, additional experiments would be performed to identify the critical variable.

\section{Method}

Subjects. The subjects were 40 male Sprague-Dawley rats approximately 90 days old at the time of testing, which is within the age range (80-90 days) used by Maier (1989). The subjects were maintained as described in Experiment 1.

Apparatus. Because the design of the restraining tubes, tail electrodes, and tailflick device used in our laboratory is modeled after the equipment J. Grau used while working with S. Maier, the test apparatus are fairly similar. There are, however, some potentially important differences. One is that we generally cover our restraining tubes to minimize the impact of distracting stimuli, whereas Maier does not. Instead, Maier tests his subjects in clear Plexiglas tubes in a room illuminated by a dim red light. Second, because Maier uses younger subjects, they are restrained in shorter tubes. To mimic these test conditions, our subjects were restrained in clear Plexiglas tubes $(17.5 \mathrm{~cm}$ in length) housed in a room illuminated by a $15-\mathrm{W}$ red lightbulb. Other details of the apparatus were the same as those described in Experiment 1.

Procedure. The subjects were administered $40 \mathrm{mg} / \mathrm{kg}$ of pentobarbital, as described in Experiment 1. (We did not attempt to equate the dose of pentobarbital used by Maier because in our laboratory that dose generally causes severe respiratory dysfunction and a high rate of attrition.) Half of the subjects also received an s.c. injection of $7 \mathrm{mg} / \mathrm{kg}$ naltrexone, the same injection regimen used by Maier (1989). The other half received an s.c. injection of saline. Fifteen minutes later, they were placed in the Plexiglas tubes and given $5 \mathrm{~min}$ to acclimate, as described by Maier (1989). Three baseline tailflick tests were then performed at 2-min intervals. The last two tests were averaged to obtain the baseline score. Next, shock electrodes were attached and half of the subjects in each drug condition were given a $5-\sec 1.0-\mathrm{mA}$ shock. The remaining subjects were treated the same way except that shock was withheld. The shock electrodes were then removed and tailflick tests were performed at $2,4,6,8$, and $10 \mathrm{~min}$ after shock.

\section{Results}

The results are depicted in Figure 6. It is clear that shocked subjects exhibited longer tailflick latencies and that the hypoalgesia was not attenuated by naltrexone.

An ANOVA verified that the groups did not differ prior to shock treatment (all $F \mathrm{~s}<1.0, p>.05$ ). An analysis of the tailflick latencies obtained after shock revealed a main effect of shock $[F(1,36)=14.85, p<.001]$. Neither the main effect of drug treatment nor its interaction with shock treatment approached statistical significance (both $F \mathbf{s}<$ $1.0, p>.05)$. Although the trials effect was significant $[F(4,144)=2.69, p<.05]$, its interactions with the between-subjects treatments did not approach statistical significance (all $F_{\mathrm{s}}<1.78, p>.05$ ).

\section{Discussion}

We found that a $5.0-\sec 1.0-\mathrm{mA}$ tailshock elicited a naltrexone-insensitive antinociception. These results mirror those obtained in Experiment 2, where we found that three shocks of the same intensity and $1.5 \mathrm{sec}$ in duration elicited a naltrexone-insensitive antinociception. Thus, in our lab-
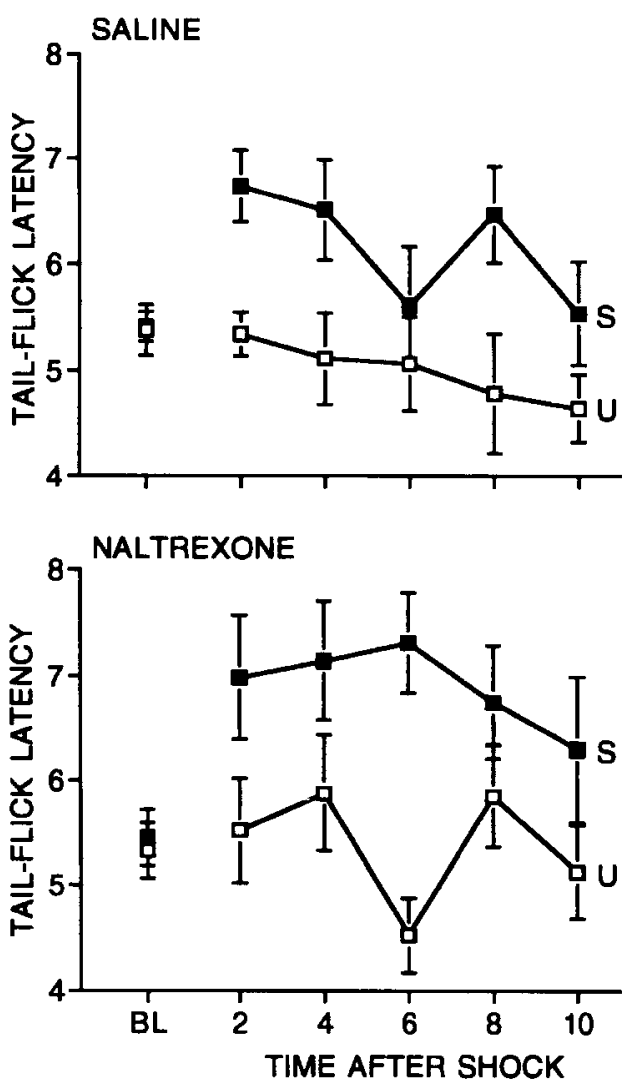

Figure 6. Tailflick latencies observed in rats that were pentobarbital-anesthetized and given either saline (top panel) or naltrexone (lower panel). Shocked rats (S, filled symbols) received a single 5-sec 1.0-mA shock, while the unshocked controls $(U$, open symbols) had the electrodes attached but did not receive any shock. Error bars indicate standard errors.

oratory, we have consistently found that the shortest shocks that produce antinociception in pentobarbital-anesthetized and decerebrate rats elicit a nonopioid antinociception.

Because one of us (J.W.G.) helped to develop the test procedures used in Maier (1989), we were able to match his test conditions quite closely. Of course, there were some variables that could not be matched (e.g., housing conditions), and consequently our results should not be construed as a failure to replicate. Rather, what the present results suggest, together with our prior work (Meagher et al., 1993; Meagher et al., 1990), is that this particular form of opioid antinociception must be observed under very limited conditions. Indeed, even Maier's own laboratory has failed to observe this effect on occasion (e.g., Watkins et al., 1984), and when it is obtained, it occurs only under a very narrow set of parameters ( 5 to $10 \mathrm{sec}$ of 1.0 -mA shock). This is quite worrisome inasmuch as it is the best evidence that the brainstem opioid system can be directly activated by afferent nociceptive information. These observations reinforce our earlier claim (Meagher et al., 1993; Meagher et al., 1990) that this putative pathway plays little, if any, functional role. This is particularly problematic given the extent to which 
widely accepted theories (e.g., Basbaum \& Fields, 1984; Watkins \& Mayer, 1982) have emphasized this mode of activation.

\section{GENERAL DISCUSSION}

On the basis of data collected in pentobarbitalanesthetized rats, Terman et al. (1984) suggested that the brainstem opioid and nonopioid antinociceptive systems were sequentially activated as shock severity was increased, and that the coulometric relationship could be used to measure shock severity. In contrast, prior work from our laboratory (Meagher et al., 1993) led us to propose that a nonopioid-to-opioid-to-nonopioid transition would emerge as shock severity was increased and that the power law provided a better measure of shock severity. The present experiments compared these alternative views.

\section{Predicting the Emergence of Antinociception}

We began by establishing the minimum shock intensity and duration needed to elicit antinociception in pentobarbital-anesthetized rats (Experiment 1). We found that three 25-sec shocks did not elicit antinociception until shock intensity reached $0.5 \mathrm{~mA}$. Conversely, three $1.0-\mathrm{mA}$ shocks did not elicit antinociception until shock duration reached $1.5 \mathrm{sec}$.

Experiment 1 also provided an opportunity to contrast the coulometric relationship and the power law. We have consistently found that brief intense shocks are more effective than long weak shocks (Grau, 1987b; Meagher et al., 1993). Such an outcome is anticipated by the power law but not by the coulometric hypothesis. However, it could be argued that the coulometric relationship failed simply because the intensity of the long weak shocks was subthreshold. Our application of the power law encounters a similar problem inasmuch as it, too, incorrectly predicts that shocks that are imperceptible, because either their duration or their intensity is subthreshold, should generate antinociception. To avoid this problem, one would have to invoke the notion of thresholds. (Of course, whether or not a stimulus is functionally imperceptible may depend upon the level of the nervous system involved.) Therefore, a fair test of the coulometric hypothesis would require that the shock schedules in question have duration and intensity values that were clearly suprathreshold. We found that even when these criteria were met, the coulometric hypothesis failed; brief intense shocks $(1.5 \mathrm{sec}, 1 \mathrm{~mA})$ produced a stronger antinociception than did long weak shocks ( $3 \mathrm{sec}$, $0.5 \mathrm{~mA}$ ), as anticipated by the power law.

We have now shown that the coulometric relationship fails to predict when antinociception will emerge in awake (Grau, 1987b), pentobarbital-anesthetized (Experiment 1), decerebrate, and spinalized rats (Meagher et al., 1993). A summary of these findings is provided in Figure 7. Notice that, in each case, as shock intensity is increased, the coulometric relationship (depicted by the dashed lines) overestimates the duration required to elicit antinociception; the actual duration required to elicit antinociception with an intense shock is much less than that predicted by the cou-
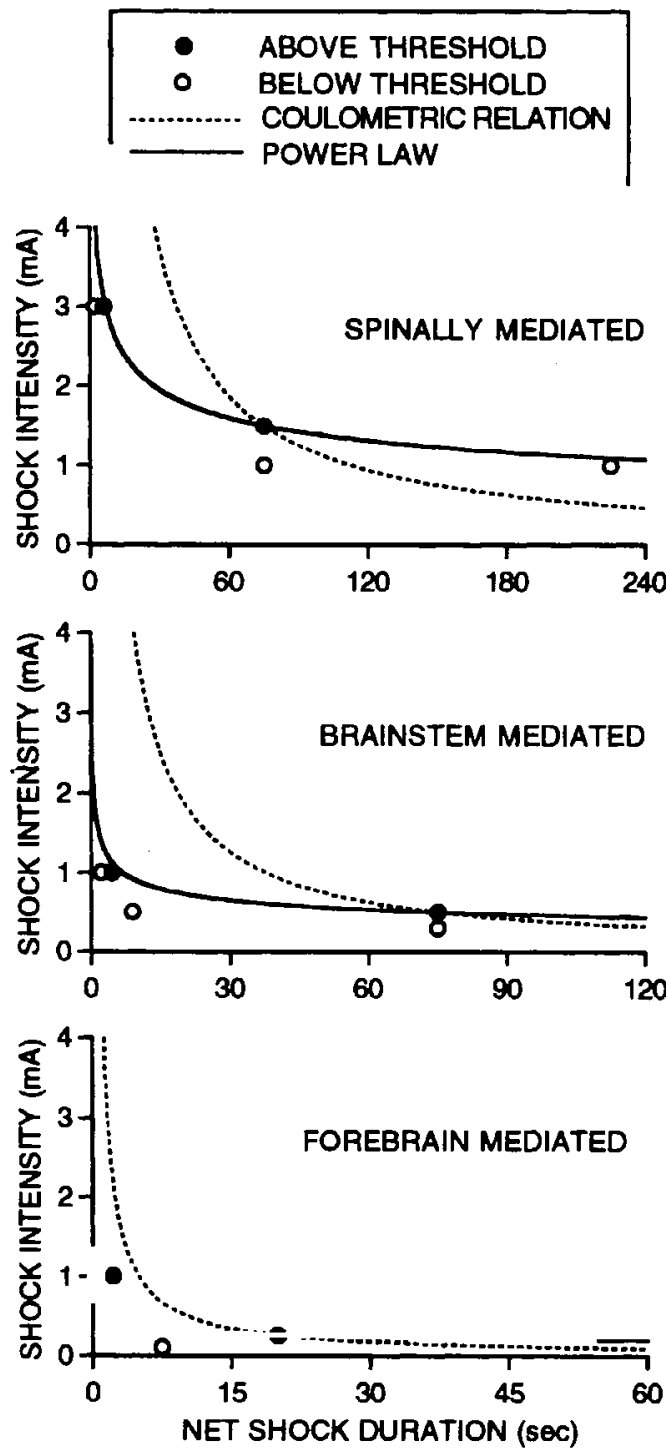

Figure 7. Summary of the minimum-shock conditions known to produce antinociception in awake (lower panel), decerebrate or pentobarbital anesthetized (middle panel), or spinalized (upper panel) rats. In each condition, the filled symbols depict the least severe shock schedule known to produce a statistically significant antinociception in our paradigm. The open symbols illustrate the most severe shock conditions tested that failed to produce antinociception. The functions displayed were derived using the coulometric relationship (dashed lines) and the power law (solid lines). In each case, the functions were anchored to the lowest intensity shock schedules that produced a significant antinociception. To derive these functions, we assumed severity values of 5,37.5, and 112.5 for the coulometric relationship and 0.16 , 6.5, and 310 for the power law. The data depicted in the upper two panels were derived from studies (Experiment 1; Meagher et al., 1993; Meagher et al., 1990) in which we independently manipulated shock duration and intensity to derive the threshold values. The data depicted in the lower panel is from Grau (1987a, 1987b) and Meagher et al. (1989). These studies provided a test of the coulometric relationship in awake rats (Grau, 1987b) and established that 0.25-mA, but not 0.1-mA, shocks produced hypoalgesia. We have not, however, established the minimum shock duration needed to induce hypoalgesia in awake rats. Consequently, it remains possible, and indeed is likely, that much less than $2.25 \mathrm{sec}$ of 1.0-mA shock would be needed to produce hypoalgesia. 
lometric relationship. Of course, one could solve this problem by using the brief intense shock schedules to anchor the functions. But then the coulometric relationship would inaccurately predict that long weak shocks, ones that have no impact on nociceptive thresholds, should generate a strong antinociception. Again, the problem is that the coulometric relationship overestimates the contribution of shock duration. The power law, in contrast, appears to provide a very good fit to the data. Moreover, it does so across a wide range of values and across different levels of the nervous system. This suggests that the power law provides a fairly general measure of shock severity. Of course, caution is still warranted, for it is unclear whether this relationship applies to other domains. Moreover, superior metrics will surely eventually be discovered, metrics that have greater generality and apply over a wider range of conditions. Indeed, it must be acknowledged that the coulometric relationship does an adequate job over a restricted range of conditions (e.g., see Figure 2 in Terman et al., 1984). The power law is superior only because it allows accurate predictions over a much wider range of shock values.

\section{Predicting the Level of the Neural Axis Involved}

What we know from the results reviewed above is that (1) the magnitude of antinociception observed in a variety of paradigms is a function of shock severity, and (2) the power law provides an excellent measure of shock severity. From these observations, we can derive another principle: The level of the nervous system involved depends on shock severity. Forebrain mechanisms appear to play a critical role in producing the antinociception observed after the least severe shock parameters that generate antinociception in intact/awake rats (Grau, 1987a; Meagher et al., 1989, 1990). Increasing shock severity produces an antinociception that is eliminated by spinal transection but not by decerebration or pentobarbital anesthesia (Experiment 1; Meagher et al., 1993; Meagher et al., 1990). Under these conditions, the afferent signal appears to activate a brainstem system (or systems) that then drives a spinal antinociceptive mechanism. Finally, even more severe shocks produce an antinociception that survives spinal transection, indicating that spinal mechanisms are being directly activated by the afferent input through an intraspinal connection (Meagher et al., 1993). Taken together, these observations suggest that, as one descends the nervous system (from the forebrain mediated pathway to intraspinally mediated modes of activation), more severe shocks are needed to engage the antinociceptive systems.

Assuming that similar thresholds operate in the intact organism, this functional organization would have important consequences for the way in which nociceptive information is processed. Because spinal mechanisms have the highest thresholds, they will allow the nociceptive input to vary over a wide range of values unchecked; the input would be attenuated only by an intraspinally mediated antinociception when the organism encountered an extremely aversive stimulus. In contrast, because forebrain systems have much lower thresholds, these systems will be engaged sooner and under much milder conditions than those needed to en- gage lower level modes of activation. Given that organisms in the natural environment will try to avoid exposure to mildly aversive stimuli and that rats in the laboratory will learn a variety of operants to avoid or escape shocks that are no more aversive than those needed to elicit a forebrainmediated antinociception (Campbell \& Masterson, 1969; Church et al., 1967), forebrain systems may maintain control over the activation of lower level antinociceptive systems under most circumstances. From this perspective, the lower level modes of activation would serve as backup mechanisms that are engaged only under the most severe conditions (Grau, 1987b; Meagher et al., 1993).

\section{Impact of Shock Severity on the Form of the Antinociception Observed}

Experiment 2 looked at the relationship between shock severity and the form of the antinociception observed. As discussed earlier, Terman et al. (1984) observed a simple opioid-to-nonopioid transition in pentobarbitalanesthetized rats. In contrast, on the basis of studies using reduced preparations (Meagher et al., 1993; Meagher et al., 1990), we expected a more complex pattern to emerge: a nonopioid-to-opioid-to-nonopioid transition. The results obtained in Experiment 2 were nearly identical to those found in decerebrate and spinalized subjects (Meagher et al., 1993; Meagher et al., 1990). Thus, the least severe shock parameters, which produce a nonopioid antinociception in decerebrate rats, also produced a nonopioid antinociception in pentobarbital-anesthetized rats. When shock severity was increased to the range that produced an opioid antinociception in spinalized rats, the antinociception observed in pentobarbital-anesthetized rats became naltrexone sensitive. Finally, as shock severity was increased even further, the antinociception became naltrexone insensitive, just as we had observed in spinalized rats. Thus, we found the nonopioid-to-opioid-to-nonopioid transition expected on the basis of our past work (Meagher et al., 1993). Moreover, the opioid-to-nonopioid transition predicted by Terman et al. (1984) appears to be embedded within our results. Consequently, if one ignores the early nonopioid component, we replicated Terman et al. Indeed, the shock parameters we found to produce an opioid-to-nonopioid transition, in both pentobarbital-anesthetized and spinalized rats, are remarkably similar to the shock parameters used by Terman et al. This observation, in conjunction with our failure to observe a brainstem-mediated opioid antinociception, has led us to suggest that Terman et al. (1984) were most likely studying a spinally mediated antinociception (Meagher et al., 1993). ${ }^{2}$

There is, however, one way in which the present results differ from those obtained in our reduced preparations. In spinalized subjects, the intermediate shock schedules $(2 \mathrm{sec}$, $3.0 \mathrm{~mA}$ or $25 \mathrm{sec}, 1.5 \mathrm{~mA}$ ) used in the present study produced an antinociception that was eliminated by naltrexone. In contrast, naltrexone only attenuated the antinociception observed in pentobarbital-anesthetized rats exposed to these same shock schedules. A similar outcome was obtained in awake rats (Meagher et al., 1993). Thus, in intact subjects, the spinally mediated opioid antinociception ap- 
pears to be superimposed upon a brainstem-mediated nonopioid antinociception. This is interesting because, in other situations, collateral inhibition appears to prevent the concurrent activation of the opioid and nonopioid antinociceptive systems (Kirchgessner, Bodnar, \& Pasternak, 1982; Steinman et al., 1990). Indeed, such a relationship is effectively built into the model proposed by Grau (1987a). What the present findings suggest is that some opioid/nonopioid systems are not linked by collateral inhibition.

\section{Predicting the Form of the Antinociception Observed}

A summary of the relationship found between shock severity and the form of the antinociception observed is presented in Figure 8. The first point to notice is how well the results obtained by Terman and his colleagues fit our own. This is particularly remarkable given that major differences existed in the way shock was applied and subjects were tested. The second point to notice is the relative fit provided by the coulometric relationship (upper panel) and the power law (lower panel). In each panel, the first three functions illustrate the thresholds for activating the forebrain, brainstem nonopioid, and spinal opioid systems, respectively. These are the same functions displayed in Figure 7 . A fourth function was added to characterize the transition from spinal opioid to nonopioid. Visually, what is hoped for is that each function partitions the data into sections that are mediated by the same neural processes. For example, focusing on the functions generated by using the power law, it is clear that the upper function (spinal nonopioid) nicely separates the shock conditions that produce a spinally mediated nonopioid antinociception from those that generate a spinally mediated opioid antinociception. Indeed, as one would hope, the function follows the transition point where mixed antinociceptive effects are observed. The next lower function (spinal opioid) separates the spinal opioid from the brainstem nonopioid (the squares that lie along and above this line illustrate antinociceptive effects that survive spinalization; Meagher et al., 1993). The third lowest function (brainstem nonopioid) then indicates the transition between the brainstem-nonopioidmediated antinociception and forebrain-mediated effects (the squares that lie along this line illustrate antinociceptive effects that survive decerebration and pentobarbital anesthesia but not spinalization; Experiments 1 and 2; Meagher et al., 1993; Meagher et al., 1990). The final function (forebrain) depicts the point at which higher neural systems begin to generate antinociception, which can be opioid, nonopioid, or mixed, depending on a variety of factors.

In contrast, the functions generated using the coulometric relationship (upper panel) do not nicely partition the results - each region contains a mixture of opioid and nonopioid antinociceptive effects, some of which are mediated at different levels of the nervous system. For example, the region bounded by the two lowest functions includes a mixture of forebrain (mixed and opioid), brainstem (nonopioid), and spinally (primarily opioid) mediated antinociceptive effects. Similar heterogeneity is observed in each of the other regions. Moreover, simply shifting the func- tions will not eliminate the violations. Thus, not only does the coulometric relationship fail to predict the emergence of antinociception, it also fails to predict the form of the antinociception observed.

The present results suggest that the power law can be used to predict whether the brainstem nonopioid, spinal opioid, or spinal nonopioid system will be engaged. It is important to note, however, that there are many circumstances in which a simple power function may not suffice. For example, consider the forebrain-mediated antinociception observed after mild shock (the region bounded by the first two functions in the lower panel of Figure 8). Fanselow (1984) proposed that the form of this hypoalgesia depended on shock severity and that the coulometric relationship could be used to measure severity. He further suggested, independently of Terman et al. (1984), that the mildest shock conditions would produce an opioid hypoalgesia and that increasing shock severity would engage a nonopioid system. However, we have shown that increasing shock severity (by increasing its duration) can produce results that go in the opposite direction, causing the hypoalgesia to become more naltrexone sensitive (Grau, 1987b). Simply adopting a different measure of shock severity, such as the power law, will not remedy this problem. Rather, what is needed is a detailed model of learning and memory (e.g., Grau, 1987a) that can accommodate the plasticity exhibited by forebrain systems.

A simple severity hypothesis fares better when dealing with lower level mechanisms, because these systems do not appear to be nearly as plastic. Indeed, we originally suggested (Grau, 1987b) that these lower level modes of activation reflected a passive, unconditioned response to aversive stimulation, a point that was later echoed by Maier (1989). To the extent that this is true, the power law can be used to predict when these antinociceptive systems will be engaged. However, here too, we now believe that we have oversimplified the story, for learning and memory-like processes appear to play a role at every level of the nervous system. For example, we have shown that a postshock distractor can speed the decay of the brainstem-mediated nonopioid antinociception, a finding that suggests that memorial mechanisms may be involved (Meagher et al., 1995). Even more surprising is that a cutaneous distractor can attenuate spinally mediated antinociceptive effects and that a conditioned antinociception (that is spinally mediated) can be established by pairing a cutaneous stimulus with tailshock (Grau, Salinas, Illich, \& Meagher, 1990). Further complications stem from the fact that mere exposure to shock can alter its consequences. For example, we (Grau et al., 1981) and Maier (1989) have shown that exposure to $205-\mathrm{sec} 1.0-\mathrm{mA}$ shocks spaced over a $20-\mathrm{min}$ period elicits a brainstem-mediated nonopioid antinociception. However, if further shock is given, this nonopioid antinociception goes away, as if the response had habituated (Grau et al., 1981; Maier, 1989). Similar habituationlike mechanisms could affect the magnitude of spinally mediated antinociceptive effects. Such plasticity will undermine the degree to which any simple measure of shock severity can, in isolation, be used to predict the form of the 

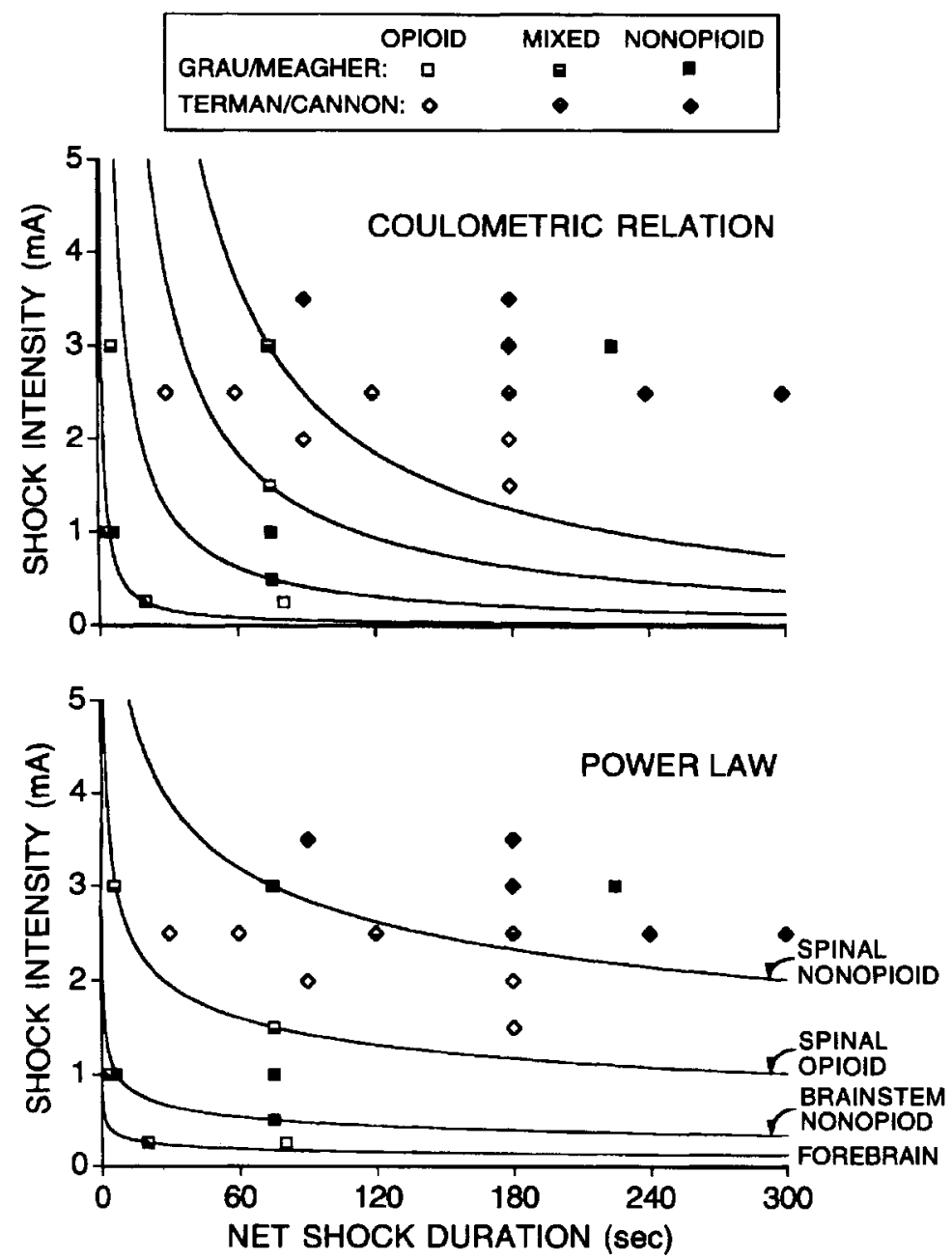

Figure 8. Summary of the shock conditions known to produce an opioid (open symbols), nonopioid (filled symbols), or mixed (half-filled symbols) antinociception in rats. This figure is based upon our studies of antinociception using awake (Grau, 1987a, 1987b), decerebrate (Meagher et al., 1993; Meagher et al., 1990), lesioned (Meagher et al., 1989), pentobarbital-anesthetized (Experiments 2 and 3), and spinalized rats (Meagher et al., 1993). In addition, for purposes of comparison, we have included the results obtained by Terman and his colleagues (Cannon et al., 1984; Terman et al., 1984). Shock conditions that failed to produce a reliable antinociception, such as $90 \mathrm{sec}$ of $1.6-\mathrm{mA}$ foot shock (Cannon et al., 1984), were not included. The functions depicted in the lower panel were generated using the power law; the functions displayed in the upper panel were derived from the coulometric relation. The first three functions in each panel are the same as those depicted in Figure 7, and accordingly are anchored to the same data points. They are designed to predict the threshold at which the forebrain, brainstem nonopioid, and spinal opioid antinociceptive systems are engaged. The last function in each panel is designed to illustrate the threshold for activating the spinal nonopioid system, and, accordingly, these functions are anchored to the least severe shock conditions that produced a robust naltrexone-insensitive antinociception in spinalized rats. To generate these functions, we assumed a severity value of 225 for the coulometric relationship and 3,500 for the power law. The squares summarize results obtained in our laboratory (Experiment 2; Grau, 1987a, 1987b; Meagher et al., 1993; Meagher et al., 1989, 1990). The diamonds summarize the results obtained by Terman and his colleagues (Cannon et al., 1984; Terman et al., 1984). In each case; the open symbols represent opioid (naltrexone reversible) and the filled symbols represent nonopioid (naltrexone did not have a significant impact) antinociceptive effects. Partially filled symbols depict examples of antinociception that contain both an opioid and a nonopioid component (naltrexone attenuated, but did not eliminate, the antinociception). For these cases, the relative sensitivity to an opioid antagonist is indicated by the relative proportion of the symbol that is filled (nonopioid) versus unfilled (opioid). The time course of this effect is indicated by the angle of the filling. In cases where naltrexone had a fairly uniform impact, a horizontal filling is employed. An angled filling is used to depict antinociceptive effects in which the impact of the antagonist varied as a function of the time of testing (e.g., the shock schedule elicited a transient nonopioid and long-lasting opioid antinociception). In cases where the same shock schedule was tested more than once, the results were averaged. 
antinociception observed; in all cases, we will need to supplement the relationship with rules that address the role of learning and memory, and this is true at every level of the nervous system. ${ }^{3}$

\section{Neural Mechanisms}

We have sought to describe the principles that govern the activation of the antinociceptive systems at different levels of the nervous system. What we have not addressed is how this molar model relates to specific pain modulatory circuits. Of particular interest is the model outlined by Fanselow (1991) and his colleagues, according to whom the opioid and nonopioid antinociception observed after moderate shock depends on the ventral and dorsolateral periaqueductal gray (PAG), respectively. Just as we assume that a nonopioid system can be directly activated at the level of the brainstem, Fanselow assumes that afferent nociceptive information can directly drive the dorsolateral PAG. Similarly, he denies that the brainstem opioid system is directly activated by afferent nociceptive information. Rather, he assumes, as we do, that higher neural systems within the forebrain play a critical role in activating the brainstem opioid system. His work complements our own by outlining the neural pathways within the forebrain that effectively drive the ventral PAG through projections from the amygdala. For situations that involve moderately intense shocks, the only other link that needs to be specified is one that allows forebrain systems to modulate the activation of a lower level nonopioid antinociceptive system (Fanselow, 1984; Grau, 1987a; Lichtman \& Fanselow, 1991; Meagher et al., 1993). Because Fanselow has not explored the impact of more severe shocks, his model is silent with regard to activation of the antinociceptive mechanisms by means of intraspinal pathways. However, his model could be readily modified to allow for these additional modes of activation.

\section{Summary and Conclusions}

In summary, the theory of pain modulation that we are suggesting differs from earlier accounts in three important ways. First, we assume that there are five distinct modes of activation: forebrain opioid, forebrain nonopioid, brainstem nonopioid, spinal opioid, and spinal nonopioid. The forebrain opioid component and the brainstem nonopioid component of our model are found in a variety of other theories (e.g., Maier, 1989; Watkins \& Mayer, 1982). What is relatively unique to our framework is that it allows for a forebrain-mediated nonopioid hypoalgesia (also see Chance, 1980; Fanselow, 1984; Lichtman \& Fanselow, 1991), it denies that the brainstem opioid system is ever directly activated by afferent nociceptive information (cf. Maier, 1989; Meagher et al., 1993; Watkins \& Mayer, 1982), and it incorporates intraspinal modes of activation. Second, we propose that the level of the nervous system involved depends on shock severity, and that severity can be measured by means of a function derived from Stevens's power law. And third, we assume that learning and memorylike processes play a role at all levels of the nervous sys- tem. This contrasts with earlier accounts (Maier, 1989; Watkins \& Mayer, 1982) which assume that low-level modes of activation reflect a passive unconditioned response to aversive stimulation.

\section{REFERENCES}

Basbaum, A. I., \& Fields, H. L. (1984). Endogenous pain control systems: Brainstem spinal pathways and endorphin circuitry. Annual Review of Neuroscience, 7, 309-338.

Camprell, B. A., \& Masterson, F. A. (1969). Psychophysics of punishment. In B. A. Campbell \& R. M. Church (Eds.), Punishment and aversive behavior (pp. 3-42). New York: Appleton-Century-Crofts.

Cannon, J. T., Prieto, G. J., Lee, A., \& Liebeskind, J. C. (1982). Evidence for opioid and non-opioid forms of stimulation-produced analgesia in rat. Brain Research, 243, 315-321.

Cannon, J. T., Terman, G. W., Lewis, J. W., \& Liebeskind, J. C. (1984). Body region shocked need not critically define the neurochemical basis of stress analgesia. Brain Research, 323, 316-319.

ChANCE, W. T. (1980). Autoanalgesia: Opiate and non-opiate mechanisms. Neuroscience \& Biobehavioral Reviews, 4, 55-67.

Church, R. M., Raymond, G. A., \& Bauchamp, R. D. (1967). Response suppression as a function of intensity and duration of punishment. Journal of Comparative \& Physiological Psychology, 63, 39-44.

D’Amour, F. E., \& SMiTh, D. L. (1941). A method for determining loss of pain sensation. Journal of Pharmacology \& Experimental Therapeutics, 72, 74-79.

FANSELOW, M. S. (1984). Shock-induced analgesia on the formalin test: Effects of shock severity, naloxone, hypophysectomy, and associative variables. Behavioral Neuroscience, 98, 79-95.

FANSELOW, M. S. (1991). The midbrain periaqueductal gray as a coordinator of action in response to fear and anxiety. In A. Depaulis \& R. Bandler (Eds.), The midbrain periaqueductal gray matter: Functional, anatomical and immunohistochemical organization (NATO ASI Series, pp. 151-173). New York: Plenum.

GRAU, J. W. (1984). The influence of naloxone on shock-induced freezing and analgesia. Behavioral Neuroscience, 98, 278-292.

GRAU, J. W. (1987a). The central representation of an aversive event maintains the opioid and nonopioid forms of analgesia. Behavioral Neuroscience, 101, 272-288.

GraU, J. W. (1987b). The variables which control the activation of analgesic systems: Evidence for a memory hypothesis and against the coulometric hypothesis. Journal of Experimental Psychology: Animal Behavior Processes, 13, 215-225.

Grau, J. W., Biles, M. K., \& Illich, P. A. (1991). The impact of naltrexone and morphine tolerance on mild shock-induced hypoalgesia. Psychobiology, 19, 85-90.

Grau, J. W., Hyson, R. L., Maier, S. F., Madden, J., \& Barchas, J. D. (1981). Long-term stress-induced analgesia and activation of the opiate system. Science, 213, 1409-1411.

Grau, J. W., Illich, P. A., Chen, P.-S., \& Meagher, M. W. (1991). Role of cholinergic systems in pain modulation: I. Impact of scopolamine on environmentally induced hypoalgesia and pain reactivity. Behavioral Neuroscience, 105, 62-81.

Grau, J. W., Salinas, J. A., Illich, P. A., \& Meagher, M. W. (1990). Associative learning and memory for an antinociceptive response in the spinalized rat. Behavioral Neuroscience, 104, 489-494.

Grisel, J. E., Fleshner, M., Watkins, L. R., \& Maier, S. F. (1993). Opioid and nonopioid interactions in two forms of stress-induced analgesia. Pharmacology. Biochemistry \& Behavior, 45, 161-172.

Hyson, R. L., Ashcraft, L. J., Drugan, R. C., Grau, J. W., \& Maier, S. F. (1982). Extent and control of shock affects naltrexone sensitivity of stress-induced analgesia and reactivity to morphine. Pharmacology, Biochemistry \& Behavior, 17, 1019-1025.

Kahneman, D., Frederickson, B. L., Schreiber, C. A., \& RedelMEIER, D. A. (1993). When more pain is preferred to less: Adding a better end. Psychological Science, 4, 401-405.

Kirchgessner, A. L., Bodnar, R. J., \& Pasternak, G. W. (1982). Naloxazone and pain-inhibitory systems: Evidence for a collateral inhibition model. Pharmacology, Biochemistry, \& Behavior, 17, 1175-1179. 
Klein, M. V., Lovaas, K. M., Terman, G. W., \& Liebeskind, J. C. (1983) The effects of decerebration and spinal transection on three discrete forms of stress-induced analgesia. Neuroscience Abstracts, 9, 795.

Lewis, J. W., Cannon, J. T., \& Liebeskind, J. C. (1980). Opioid and nonopioid mechanisms of stress analgesia. Science, 208, 623-625.

Lichtman, A. H., \& Fanselow, M. S. (1991). Opioid and nonopioid conditioned analgesia: The role of spinal opioid, noradrenergic, and serotonergic systems. Behavioral Neuroscience, 105, 687-698.

MAIER, S. F. (1989). Determinants of the nature of environmentally induced hypoalgesia. Behavioral Neuroscience, 103, 131-143.

Maier, S. F., Davies, S., Grau, J. W., Jackson, R. L., Morrison, D. H., MoYe, T., MAdDEN, J., \& BARChAS, J. D. (1980). Opiate antagonists and long-term analgesic reaction induced by inescapable shock in rats. Journal of Comparative \& Physiological Psychology, 94, 1172-1183.

Meagher, M. W., Barter, J., King, T. E., \& Grau, J. W. (1995). Presentation of a distractor speeds the decay of a pentobarbital-insensitive nonopioid hypoalgesia in rats. Psychobiology, 23, 314-321.

Meagher, M. W., Chen, P.-S., Salinas, J. A., \& Grau, J. W. (1993) Activation of the opioid and nonopioid hypoalgesic systems at the level of the brainstem and spinal cord: Does a coulometric relation predict the emergence or form of environmentally induced hypoalgesia? Behavioral Neuroscience, 107, 493-505.

Meagher, M. W., Grau, J. W., \& King, R. A. (1989). The role of the frontal cortex in analgesia: Lesions of the frontal cortex block the analgesia observed after brief, but not long, shocks. Behavioral Neuroscience, 103, 1366-1371.

Meagher, M. W., Grau, J. W., \& King, R. A. (1990). The role of supraspinal systems in environmentally induced antinociception: The effects of spinalization and decerebration on brief and long shockinduced antinociception. Behavioral Neuroscience, 104, 328-338.

MelzaCK, R., \& WaLL, P. D. (1965). Pain mechanisms: A new theory. Science, 150, 971-979.

Steinman, J. L., Faris, P. L., Mann, P. E., Olney, J. W., Komisaruk, B. R., WILLIS, W. D., \& BoDNAR, R. J. (1990). Antagonism of morphine analgesia by nonopioid cold-water swim analgesia: Direct evidence for collateral inhibition. Neuroscience \& Biobehavioral Reviews, 14, 1-7.

STEVENS, S. S. (1962). The surprising simplicity of sensory metrics. American Psychologist, 17, 29-39.

Stevens, S. S., Carton, A. S., \& Shickman, G. M. (1958). A scale of apparent intensity of electric shock. Journal of Experimental Psychology, 56, 328-334.

Terman, G. W., Shavit, Y., Lewis, J. W., Cannon, J. T., \& Liebeskind, J. C. (1984). Intrinsic mechanisms of pain inhibition: Activation by stress. Science, 226, 1270-1277.

Watkins, L. R., Drugan, R., Hyson, R. L., Moye, T. B., Ryan, S. M., MAYER, D. J., \& MAIER, S. F. (1984). Opiate and non-opiate analgesia induced by inescapable tail-shock: Effects of dorsolateral funiculus lesions and decerebration. Brain Research, 291, 325-336.

Watkins, L. R., Kinscheck, I. B., \& MayeR, D. J. (1983). The neural basis of footshock analgesia: The effect of periaqueductal gray lesions and decerebration. Brain Research, 276, 317-324.

WATKINS, L. R., \& MAYER, D. J. (1982). Organization of endogenous opiate and nonopiate pain control systems. Science, 216, 1185-1192.

WATKINS, L. R., \& MAYER, D. J. (1986). Multiple endogenous opiate and nonopiate analgesic systems: Evidence of their existence and clinical implications. In D. D. Kelly (Ed.), Stress-induced analgesia (Annals of the New York Academy of Sciences, Vol. 467, pp. 273-299). New York: New York Academy of Sciences.

Watkins, L. R., Wiertelak, E. P., Grisel, J. E., Silbert, L. H., \& MAIER, S. F. (1992). Parallel activation of multiple spinal opiate systems appears to mediate 'non-opiate' stress-induced analgesias. Brain Research, 594, 99-108.

\section{NOTES}

1. "Brief" is defined here as a shock schedule in which the interval between the onset of the first shock and offset of the last does not span more than $5 \mathrm{~min}$. Because of space limitations, we will not try to integrate this work with studies using longer shock schedules (e.g., 20 to $100 \mathrm{~min}$ of intermittent shock), schedules that appear to rely on other neurobiological and psychological systems (for a discussion of this issue, see Grau, 1987a; Grau, Illich, Chen, \& Meagher, 1991; or Maier, 1989).

2. A basic question raised by this work is: Why did Terman et al. (1984) not observe the early nonopioid component found in the present study? There are a number of potential answers to this question. One is that the early nonopioid component was actually present in their data, for it is clear from their figures (see p. 1272) that naltrexone did not eliminate the antinociception observed after the least severe shock parameters. However, it is difficult to judge the magnitude of this effect because exposure to the shock environment per se appeared to induce a slight nonopioid antinociception in the unshocked controls. Yet another hint of an early nonopioid antinociception can be found in a study by Cannon, Terman, Lewis, and Liebeskind (1984). These researchers compared the impact of $90 \mathrm{sec}$ of shock applied to either the front or rear paws at an intensity of $1.6,2.0$, or $3.5 \mathrm{~mA}$. They found that only the intermediate shock schedule produced an naltrexone-sensitive antinociception; the least severe shock schedule produced small antinociception that was naltrexone insensitive. However, here too, it is difficult to assess the magnitude of the antinociception, in this case, because they did not use unshocked controls. Thus, the most we can conclude is that there is a hint of an early nonopioid component in their studies. Furthermore, even if one is willing to accept this evidence, it is clear that the early nonopioid component observed by Cannon et al. (1984) was fairly transient (lasting just a few minutes) and weak (never approaching the magnitude of the antinociception elicited by the other shock schedules). In contrast, we have described a brainstem-mediated nonopioid antinociception that is both long lasting (up to $10 \mathrm{~min}$ ) and relatively strong (similar in magnitude to other examples of environmentally induced antinociception observed in our laboratory). Why did Terman and his colleagues not observe an equally strong antinociception? Recent work suggests that a basic procedural difference may account for the discrepancy. Our paradigm allowed us to test subjects while they remained undisturbed in the experimental apparatus. In addition, the apparatus was covered to minimize exposure to extraneous stimuli. These steps were taken because we had found that a postshock distractor could cause antinociception to decay more rapidly (Grau, 1987a). We originally assumed that forebrain systems mediated the effect of distracting stimuli (Grau, 1987a, 1987b). However, we recently found that a postshock distractor (a flashing light) had a similar impact on the brainstem-mediated nonopioid antinociception observed after three 25-sec 1.0-mA tailshocks (Meagher et al., 1995). This is important because Terman et al. (1984) had to remove their subjects from the shock context in order to test pain reactivity. This would effectively expose subjects to a variety of distracting visual stimuli, which in turn would attenuate the brainstem-mediated nonopioid component and explain why these authors failed to observe a strong nonopioid antinociception after their least severe shock schedules.

3. Other issues, beyond the plasticity inherent in the systems, can complicate the application and derivation of the power law. In particular, special attention must be paid to the nature of the dependent variable. What we have done is make the simplest assumption possible. All that we have asked is whether the shock schedule in question produces a significant antinociception. In effect, we treated our dependent measure (tailflick latencies) as a categorical variable. If we had set as our task deriving a rule that could be used to predict the magnitude of the antinociception observed, we would have been faced with a much more daunting task, for we would then have to specify an equation to describe our dependent variable. This is not a trivial issue, for our scale is probably ordinal at best and the behavioral response is constrained by an imposed ceiling (the cutoff latency used to prevent tissue damage). Without a simple interval scale, it would be difficult to unravel the extent to which nonlinear changes in the behavior observed were due to the function that describes our independent variable versus the nonlinearity inherent in our dependent variable.

(Manuscript received March 16, 1995; revision accepted for publication August 16, 1995.) 